\title{
PLANTIO IRRIGADO DE BANANEIRAS RESISTENTES À SIGATOKA-NEGRA CONSORCIADO COM CULTURAS ANUAIS ${ }^{1}$
}

\author{
ILDEU DE SOUZA², MARLON CRISTIAN TOLEDO PEREIRA ${ }^{3}$, \\ REGINA CÁSSIA FERREIRA RIBEIRO ${ }^{4}$, SÍLVIA NIETSCHE ${ }^{5}$, \\ VICTOR MARTINS MAIA ${ }^{6}$, JOÃO PAULO LEMOS ${ }^{7}$
}

RESUMO - Com o objetivo de avaliar o plantio irrigado de bananeiras resistentes à Sigatoka-negra consorciado com cultura anuais, na região norte de Minas Gerais, um experimento foi instalado na Fazenda Experimental do Departamento de Ciências Agrárias da Universidade Estadual de Montes Claros, Câmpus de Janaúba-MG. O experimento foi conduzido no período de abril de 2006 a julho de 2007, delineado em blocos casualizados, segundo um esquema de parcelas subdivididas $3 \times 5$, tendo na parcela as três variedades de bananeiras: Pacovan Ken, Caipira e Thap Maeo, e na subparcela quatro culturas intercalares: FeijãoPérola, Quiabo-Dardo, Melancia-Crimson-Sweet e Feijão-Caupi, e a testemunha (sem cultura intercalar), com três repetições. Ao todo, foram 756 bananeiras, em 45 parcelas, com 6 plantas úteis cada, constituindo a cultura principal. As culturas intercalares ocuparam as entrelinhas da bananeira, tanto aquelas com as linhas de irrigação como sem linha de irrigação. O plantio da bananeira e das culturas intercalares foi feito no mesmo período, utilizando-se do espaçamento de 3,0 $\mathrm{m}$ entre as linhas e 2,0 $\mathrm{m}$ entre as covas de bananeira, com microaspersores espaçados de $6 \mathrm{~m}$. Avaliaram-se as características vegetativas e reprodutivas das variedades de bananeiras, no primeiro ciclo. Não foi observado efeito significativo dos cultivos intercalares sobre as variedades de bananeiras, com exceção do número de dias do plantio ao florescimento e do número de dias do plantio à colheita das variedades de bananeiras. O uso do feijão-caupi promoveu atraso no ciclo de produção das três variedades de bananeiras Pacovan-Ken, Caipira e Thap Maeo. Termos para indexação: Musa spp., cultivos intercalares, variedades.

\section{IRRIGATED CULTIVATION OF BANANA RESISTANT TO BLACK SIGATOKA, WITH ANNUAL INTERCROPS}

\begin{abstract}
To assess the irrigated cultivation of banana resistant to black Sigatoka, intercropped with annual crops in the northern region of Minas Gerais, a trial was conducted on an experimental farm of the Universidade Estadual de Montes Claros, in Janaúba-MG. The experiment was carried out from April 2006 to July 2007, in a 3 x 5 randomized block design with split plots. The plots consisted of three banana varieties (Pacovan Ken, Caipira and Thap Maeo) and subplots of four interim crops (common bean Pearl, okra Dart, watermelon Crimson Sweet and cowpea), with three replications and a control (banana without intercrop). Altogether 756 banana plants were considered, in 45 plots, using 6 central banana plants per plot, representing the main crop. The intercrops were planted in the banana inter rows, in those with and those without the irrigation pipeline. The banana and intercrops were planted in the same period. Banana plants were spaced $3.0 \mathrm{~m}$ between rows and $2.0 \mathrm{~m}$ between plants and irrigated by micro sprinklers spaced $6 \mathrm{~m}$ apart. Vegetative and reproductive characteristics of the banana varieties were evaluated in the $1^{\text {st }}$ cycle. No significant effect of the crops on the banana varieties was observed, except for the traits number of days from planting to flowering and number of days from planting to harvest of the banana varieties. The cowpea use promoted delay at the crop cycle of three varieties of banana plants Pacovan Ken, Caipira e Thap Maeo.
\end{abstract}

Index terms: Musa spp., interim crops, varieties.

\footnotetext{
${ }^{1}$ (Trabalho 014-09). Recebido em: 07-01-2009. Aceito para publicação em: 23-06-2009. Trabalho de dissertação de Ildeu de Souza, para obtenção do título de Mestrado em Produção Vegetal no Semi-Árido, junto à Universidade Estadual de Montes Claros, JanaúbaMG. Suporte financeiro do CNPq para a experimentação de campo e da FAPEMIG para bolsas.

${ }^{2}$ Eng. Agrônomo, Empresa de Assistência Técnica e Extensão Rural do Estado de Minas Gerais (EMATER-MG). ildeu.souza@emater.mg.gov.br; ${ }^{3}$ Eng. Agrônomo, D.Sc., Universidade Estadual de Montes Claros, Janaúba-MG, marlon.pereira@unimontes.br;

${ }^{4}$ Eng. Agrônoma, D.Sc., Universidade Estadual de Montes Claros, Janaúba-MG, regina.ribeiro@unimontes.br;

${ }^{5}$ Eng. Agrônoma, D.Sc., Universidade Estadual de Montes Claros, Janaúba-MG, silvia.nietsche@unimontes.br;

${ }^{6}$ Eng. Agrônomo, D.Sc., Universidade Estadual de Montes Claros, Janaúba-MG, victor.maia@unimontes.br;

${ }^{7}$ Estudante de graduação, $10^{\circ}$ período de agronomia, Universidade Estadual de Montes Claros,Janaúba-MG, agrolemos@hotmail.com.
} 


\section{INTRODUÇÃO}

A banana é uma das frutas mais produzidas e consumidas no Brasil e no mundo. Sua produção mundial, em 2007, foi superior a 70 milhões t, e a brasileira foi de 7,0 milhões $t$ (FAO, 2008). Esta produção coloca o País como terceiro produtor mundial, atrás apenas da Índia (21,7 milhões t) e da China (7,3 milhões t) (FAO, 2008; IBGE, 2008). A produção mineira de banana ocupa a quarta colocação no cenário nacional, com quase 8\% do total produzido, em 2006 (IBGE, 2008). A produtividade média no Estado de Minas Gerais atingiu 14,614 t.ha ${ }^{-1}$, com área plantada de 37,67 mil ha e produção de 550,5 mil t em 2005 (Agrianual, 2007). A bananicultura é parte importante da fonte de renda dos pequenos produtores e da alimentação das camadas mais carentes da população, sobretudo no meio rural das regiões Norte e Nordeste brasileiro. É cultivada predominantemente em pequenas propriedades, sendo de grande importância para a alimentação, fixação do homem no campo, geração de emprego, renda para as famílias e divisas para o País (Cordeiro, 2000).

O norte de Minas Gerais destaca-se como uma das principais regiões produtoras de bananas $\mathrm{e}$ o maior polo produtor da variedade Prata no Brasil, adotando alta tecnologia de produção e obtendo elevadas produtividades. Com cerca de 11,692 mil ha em produção e produtividade média de 21,263 tha ${ }^{-1}$, em 2006 (IBGE, 2008), a cadeia produtiva da bananicultura no norte de Minas Gerais é responsável por mais de 30.000 empregos diretos (Casassanta, 2001). A Sigatoka-negra, causada pelo fungo Mycosphaerella fijiensis Morelet, já presente em várias regiões brasileiras, é uma doença muito agressiva e a mais temida em todo o mundo, porque ataca as folhas da bananeira com grande intensidade, causando enormes prejuízos devido ao seu controle oneroso. Com a disseminação do patógeno em várias regiões brasileiras e a possibilidade deste atingir os bananais da região norte mineira, toda a população envolvida com a cadeia produtiva da banana sentirá seus efeitos. A Sigatoka-negra não apresenta restrições para a alimentação, utilizando-se dos frutos, com relação aos aspectos nutricional e sanitário, mas afeta drasticamente a produção da planta (Agrianual, 2007).

Embora existam muitas variedades de bananeiras plantadas no Brasil, mas quando se considera aquelas cujos frutos têm boa aceitação pelo consumidor, esse número fica bastante reduzido. As variedades Prata, Prata-Anã, Nanica, Nanicão e Maçã estão entre as preferidas pelos consumidores brasileiros, sendo todas suscetíveis à Sigatoka-negra (Cordeiro et al., 2006). Com a chegada desta doen- ça às regiões brasileiras mais populosas, maiores produtoras e consumidoras de bananas, há grande preocupação relacionada a sua produção, tanto nos aspectos econômicos, quanto no aspecto do seu controle sanitário. Portanto, o plantio de variedades de bananeiras resistentes à Sigatoka-negra é o método mais simples, barato e seguro para conviver com esta enfermidade. A adoção de culturas intercalares associadas a estas variedades é uma forma de amortizar os custos de implantação e tornar a atividade mais rentável, principalmente para os pequenos produtores, que são maioria no plantio de bananeiras.

Existem poucos trabalhos na literatura nacional e mundial sobre os efeitos de cultivos intercalares na cultura da bananeira. Há carência de trabalhos de pesquisa que avaliem a prática de cultivos intercalares ou consorciação de culturas com a bananeira no norte de Minas Gerais. Os sistemas de explorações agrícolas em consórcio são tradicionais entre os pequenos agricultores, que podem utilizar melhor a mão de obra disponível nas suas propriedades, para ocupação, geração de emprego e renda. Além dessas vantagens, a utilização da área livre na fase de inicial de culturas de espaçamento largo, como a bananeira, apresenta benefícios como cobertura do solo, produção de matéria orgânica, ciclagem de nutrientes, fixação de nitrogênio ao solo (Carvalho et al., 2002b), e propicia ao agricultor a produção de alimentos para a segurança alimentar, num período em que ainda não tem produção de bananas. Outrossim, também é preciso salientar que muitas culturas anuais podem ser portadoras de pragas e doenças, possíveis de serem transmitidas para a bananeira, a exemplo do vírus CMV das cucurbitáceas e do nematoide Meloidogyne no quiabo e feijão (Moreira, 1999), e devem ser monitoradas. Daí a importância de se escolher adequadamente a cultura intercalar. Isto justifica o aprofundamento de estudos científicos que proporcionem tecnologias que estejam ao alcance do agricultor familiar. Procurou-se então, através desta pesquisa, realizar um estudo da viabilidade agronômica do cultivo das bananeiras Pacovan-Ken, Caipira e Thap-Maeo, todas resistentes à Sigatoka-negra, em consórcio com as culturas anuais, na região de Janaúba, norte de Minas Gerais.

\section{MATERIAL E MÉTODOS}

O ensaio foi realizado na Fazenda Experimental da Universidade Estadual de Montes Claros (Unimontes), Câmpus de Janaúba, Minas Gerais. O solo da área experimental, sob vegetação de caatinga, classificado como Latossolo Amarelo distrófico, de textura média, com muitos murundus (pequenas 
elevações de terra, de até $2 \mathrm{~m}$ de altura, geralmente arredondadas, provavelmente formadas por insetos), primeiro ano de exploração agrícola. A precipitação pluviométrica média histórica da região é de 750 mm anuais, com distribuição muito irregular durante o ano; a temperatura média anual num período de dez anos é de $26^{\circ} \mathrm{C}$ e mínima de $16^{\circ} \mathrm{C}$. O clima da região é classificado como Aw, conforme Köeppen (Antunes, 1994).

Amostras do solo foram coletadas e analisadas e apresentaram os seguintes resultados: a) área com murundus (profundidade 0-20 cm): $\mathrm{pH}($ em água $)=4,1 ; \mathrm{Ca}^{+2}=1,6$ cmolc. $\mathrm{dm}^{-3} ; \mathrm{Mg}^{+2}$ $=0,5$ cmolc. $\mathrm{dm}^{-3} ; \mathrm{P}=6,6 \mathrm{mg} \cdot \mathrm{dm}^{-3} ; \mathrm{K}^{+}=53 \mathrm{mg} \cdot \mathrm{dm}^{-3}$; $\mathrm{MO}=0,8$ dag. $\mathrm{kg}^{-1} ; \mathrm{Al}^{+3}=0,2$ cmolc. dm $\left.{ }^{-3} ; \mathrm{a} 1\right)$ área com murundus (profundidade 20-40 cm): $\mathrm{pH}$ (em água) = 3,9; $\mathrm{Ca}^{+2}=2,2$ cmolc. $\mathrm{dm}^{-3} ; \mathrm{Mg}^{+2}=$ 0,6 cmolc.dm ${ }^{-3} ; \mathrm{P}=1,5 \mathrm{mg} \cdot \mathrm{dm}^{-3} ; \mathrm{K}^{+}=31 \mathrm{mg} \cdot \mathrm{dm}^{-3}$; $\mathrm{MO}=0,4$ dag. $\mathrm{kg}^{-1} ; \mathrm{Al}^{+3}=0,2$ cmolc. $\mathrm{dm}^{-3} ; \mathrm{b}$ ) área sem murundus (profundidade $0-20 \mathrm{~cm}$ ): $\mathrm{pH}($ em água $)=4,5 ; \mathrm{Ca}^{+2}=1,5$ cmolc. $\mathrm{dm}^{-3} ; \mathrm{Mg}^{+2}=$ 0,4 cmolc.dm ${ }^{-3} ; \mathrm{P}=12,3 \mathrm{mg} . \mathrm{dm}^{-3} ; \mathrm{K}^{+}=79$ mg.dm ${ }^{-3}$; $\mathrm{MO}=1,1$ dag. $\mathrm{kg}^{-1} ; \mathrm{Al}^{+3}=0,2$ cmolc. $\mathrm{dm}^{-3} ; \mathrm{b} 1$ ) área sem murundus (profundidade 20-40 cm): $\mathrm{pH}$ (em água) = 4,0; $\mathrm{Ca}^{+2}=0,3$ cmolc. $\mathrm{dm}^{-3} ; \mathrm{Mg}^{+2}=0,1$ cmolc. $\mathrm{dm}^{-3} ; \mathrm{P}$ $=4,7 \mathrm{mg} \cdot \mathrm{dm}^{-3} ; \mathrm{K}^{+}=59 \mathrm{mg} \cdot \mathrm{dm}^{-3} ; \mathrm{MO}=0,8 \mathrm{dag} \cdot \mathrm{kg}^{-1}$; $\mathrm{Al}^{+3}=0,2$ cmolc. $\mathrm{dm}^{-3}$.

O experimento foi conduzido no período de abril de 2006 a julho de 2007, instalado no delineamento em blocos casualizados, segundo um esquema de parcelas subdivididas ( $3 \times 5$ ), tendo nas parcelas três variedades de bananeiras Pacovan-Ken, Caipira e Thap-Maeo e, nas subparcelas, quatro culturas intercalares e a testemunha (sem cultura intercalar): Feijão-Pérola (Phaseolus vulgaris L.), Quiabo-Dardo (Abelmoschus esculentus L.), Melancia-Crimson-Sweet (Citrullus lanatus Schrad) e Feijão-Caupi (Vigna unguiculata (L.) Walp.), com três repetições (Figura 1). Foi empregado o sistema de irrigação por microaspersão.

Para as avaliações realizadas no cultivo da bananeira, foram utilizadas seis plantas úteis por parcela, enquanto nas culturas intercalares a área útil correspondeu a seis plantas de bananeira, na linha dos microaspersores e nas linhas sem microaspersores, conforme o esquema demonstrado nas Figuras 1 e 2. Os microaspersores foram instalados na distância de $6 \mathrm{~m}$. O espaçamento da bananeira foi de $3 \mathrm{~m}$ entre linhas por $2 \mathrm{~m}$ na linha, e as culturas intercalares foram implantadas na faixa central das entrelinhas das bananeiras úteis e das entrelinhas destas com as bordaduras (Figura 2), deixando-se um espaço igual ou maior que $0,5 \mathrm{~m}$ entre as culturas intercalares e a linha da bananeira.
As adubações e os tratos culturais foram executados com base no resultado da análise de solo e nas recomendações para a região. O preparo do terreno constou das operações de roçagem, subsolagem, aração e gradagens, correção com 1,5 t de calcário dolomítico por ha, a lanço, antes da aração. Foi instalado o sistema de irrigação, abertos sulcos no espaçamento das linhas de bananeiras, nos quais se marcaram as covas e colocados os adubos de plantio: $500 \mathrm{~g}$ de superfosfato simples, $5 \mathrm{~kg}$ de esterco de curral e 5 litros de munha de carvão, por cova. As mudas de bananeiras foram provenientes de cultivo in vitro, do laboratório da Unimontes, Câmpus de Janaúba.

As culturas intercalares foram implantadas no mesmo período do plantio das mudas de bananeira, ou seja, em cinco de abril de 2006. A adubação de cobertura foi aplicada mensalmente, a partir dos 30 dias após o plantio, utilizando-se, por cova, de $75 \mathrm{~g}$ de ureia (nos dois primeiros meses), $75 \mathrm{~g}$ de ureia e $85 \mathrm{~g}$ de cloreto de potássio (a partir do $3^{\circ}$ mês), acrescidos de $20 \mathrm{~g}$ de ácido bórico, $5 \mathrm{~g}$ de sulfato de cobre, $40 \mathrm{~g}$ de sulfato de zinco e $50 \mathrm{~g}$ de sulfato de magnésio (de 4 em 4 meses), a partir do $4^{\circ}$ mês. Os fertilizantes de cobertura foram aplicados manualmente sobre o solo, em círculo distante 40 cm do pseudocaule, quando a família de plantas estava em formação, e em meia-lua na frente da planta-neta, a $40 \mathrm{~cm}$ de distância, quando a família já se encontrava definida.

Os tratos culturais realizados constaram de capinas manuais, sempre que necessárias, retirada de folhas velhas, desbrotas e da retirada do coração, após a formação dos frutos. O manejo da irrigação foi realizado com base em dados climatológicos locais e em resultados de análise de solo. As plantas foram irrigadas com água fornecida de acordo com a evapotranspiração potencial de referência (ETo), média dos últimos cinco dias, utilizando-se do coeficiente de culturas (Kc) de 0,9 e conforme a equação Penman - Monteith. Como as variedades de bananeiras utilizadas são resistentes às principais doenças, Sigatoka-negra e amarela e Mal-do-panamá, e a cultura foi monitorada quanto ao aparecimento de pragas, não foi feito nenhum controle fitossanitário. A colheita foi iniciada em abril de 2007 e estendeu-se até o final de julho do mesmo ano. O ponto de colheita foi definido pela observação da aparência externa do fruto, aliada à data da emissão do cacho, para cada variedade. O cacho colhido foi transportado para um galpão, no intervalo máximo de duas horas depois de colhido. As medições e pesagens foram executadas no mesmo dia da colheita. As culturas intercalares foram 
colhidas e avaliadas.

Avaliaram-se as características vegetativas e reprodutivas de cada planta útil de bananeira. Para isto, determinaram-se o número de folhas verdes, consideradas assim aquelas com cinquenta por cento ou mais de área verde; altura das plantas, medida entre o solo e a base da última folha/ engaço; perímetro do pseudocaule (ao nível do solo e a $30 \mathrm{~cm}$ do solo), na data da emissão do cacho e da colheita. As datas da emissão do cacho e da colheita foram anotadas, para cálculo do ciclo das três variedades de bananeiras. Os cachos foram avaliados anotando-se a sua massa, número e massa das pencas e do engaço, número de frutos em cada penca, comprimento e diâmetro do fruto central da fileira distal de cada penca, massa, diâmetro e perímetro da ráquis feminina. Os resultados foram avaliados com auxílio do software SAEG (Sistema de Análises Estatísticas e Genéticas), versão 5.0, por meio de análise de variância, sendo as médias dos tratamentos comparadas pelo Teste de Tukey, a $5 \%$ de probabilidade.

\section{RESULTADOS E DISCUSSÃO}

De acordo com a análise de variância, não houve diferenças significativas do efeito dos diversos consórcios ou cultivos intercalares nas variedades de bananeiras para a maioria das características analisadas, com exceção do número de dias do plantio ao florescimento e número de dias do plantio à colheita (Tabelas 2 e 3). Também não foram constatados efeitos significativos de interação entre as variedades de bananeiras e os cultivos consorciados. No entanto, houve diferenças significativas entre as três variedades de bananeiras, para a maioria das características avaliadas, exceto para a massa dos frutos do cacho, massa dos cachos e da produtividade (Tabela 4).

A variedade Pacovan-Ken apresentou maior altura da planta (3,51 m), seguida pela Thap-Maeo (3,15 m) e pela Caipira (2,67 m), independentemente da cultura intercalar (Tabela 1). Estes valores são compatíveis com os encontrados por Gonçalves et al. (2008), em Janaúba, onde a Caipira apresentou plantas mais baixas, seguidas pela altura da ThapMaeo, e por Donato et al. (2004), com a PacovanKen, em Guanambi-BA. As plantas apresentaram alturas próximas de $3 \mathrm{~m}$, estando de acordo com resultados observados por Silva et al. (2000). A altura das plantas influi nos aspectos de densidade de plantio e manejo da cultura, interferindo na produção. Variedades de porte mais baixo podem ser plantadas de forma mais adensada, o que significa vantagem para o produtor, podendo obter maior produtividade, desde que não afete a qualidade dos frutos (Belalcázar Carvajal, 1991).

O maior perímetro do pseudocaule ao nível do solo e a $30 \mathrm{~cm}$ do solo foi observado na variedade Pacovan-Ken, com 84 e $73 \mathrm{~cm}$, respectivamente, demonstrando maior vigor vegetativo. No entanto, devido ao elevado porte, a Pacovan-Ken apresentou problemas com o tombamento de plantas na época de ventos fortes. As variedades Caipira e Thap-Maeo apresentaram valores semelhantes, 64 e $70 \mathrm{~cm}$, respectivamente, para esta característica, não havendo diferenças significativas entre ambas. $\mathrm{O}$ valor encontrado na Pacovan-Ken é muito aproximado dos 72,44 cm registrados por Donato et al. (2004), em Guanambi-BA. A altura de plantas e o perímetro do pseudocaule, associados à massa do cacho, são características decisivas no aspecto de tombamento de plantas e/ou quebramento do pseudocaule pela ação dos ventos (Teixeira, 2001).

O número de folhas vivas no florescimento variou de 13,1 por planta na variedade Caipira a 15,5 na Pacovan-Ken, esta não apresentando diferença da Thap-Maeo, que foi de 14,7 (Tabela 1). Em virtude de as variedades estudadas serem resistentes às doenças foliares, Sigatokas-amarela e negra, a desfolha foi realizada apenas quando as folhas amareleciam por senescência natural ou quebravam. Os resultados foram semelhantes aos encontrados por Rodrigues et al. (2007) em Nova Porteirinha, na variedade Caipira, por Gonçalves et al. (2008), em Janaúba, e por Santos et al. (2007), nas variedades Caipira e Thap-Maeo, em Jataí-GO. O número de folhas vivas na emissão do cacho verificado na Pacovan-Ken $(15,5)$ foi maior que o número constatado de 13,1, por Donato et al. (2006) em Guanambi-BA, provavelmente devido a diferenças no número de dias do plantio ao florescimento, que foi de 129 dias, contra 246 dias em Guanambi. Este descritor é importante na avaliação de variedades, pois poderá influenciar no desenvolvimento do cacho, o qual depende diretamente da taxa de fotossíntese da planta (Alves, 1999). As folhas são responsáveis pela produção de fotoassimilados que se acumularão nos frutos. O número de folhas vivas na colheita variou de 9,2 a 9,9, não sendo observadas diferenças significativas entre as variedades estudadas. Quanto maior o número de folhas vivas ou funcionais durante o ciclo produtivo, maior potencial de produção terá a planta (Pereira, 1997). Por isto, é interessante ressaltar que a Pacovan-Ken apresentou maior número de folhas na emissão do cacho (Tabela 1), menor tempo entre o plantio e o florescimento, e maior período de dias entre a emissão do cacho e a colheita (Tabela 3). 
Todas as variedades apresentaram mais de 13 folhas vivas na floração e mais de 9 na colheita, valores superiores aos observados por Silva et al. (2000). A manutenção do maior número de folhas do florescimento à colheita é de grande importância, pois as folhas é que garantirão o enchimento dos frutos e, após o florescimento, a bananeira não mais emite folhas (Rodrigues et al., 2007).

Na média das três variedades de bananeiras, o maior período do plantio ao florescimento e do plantio até a colheita ocorreu no consórcio do feijãocaupi (Tabela 2), o que pode estar relacionado com o ciclo maior do caupi (141 dias), comparado ao ciclo das outras culturas intercalares. O caupi é de crescimento ramalhoso e indeterminado, com maior cobertura do solo, em intensidade e tempo, podendo ter influenciado no atraso do desenvolvimento da bananeira. O número de dias do plantio ao florescimento e o número de dias do plantio à colheita foram maiores na variedade Caipira, ao passo que a variedade mais precoce foi a Thap-Maeo, com 390 dias. A variedade Pacovan-Ken apresentou menor ciclo do plantio ao florescimento, mas o período do florescimento até a colheita foi mais longo (Tabela $3)$.

A massa e a circunferência do engaço foram maiores na variedade Pacovan Ken e menor na ThapMaeo (Tabela 4), fator este relacionado à genética de cada variedade. Engaços mais pesados e mais grossos suportam frutos maiores e mais pesados. Os descritores número de pencas, número e massa dos frutos e massa dos cachos (Tabela 4) possuem estreita relação entre si e expressam diretamente a produtividade, não podendo ser considerados isoladamente na escolha de uma variedade, pois outros caracteres relacionados aos frutos, como massa, comprimento, diâmetro, sabor e resistência ao despencamento, devem ser considerados neste processo (Silva et al., 2002a).

O número de pencas variou significativamente, de 7,1 na variedade Pacovan-Ken, para 8,7 na Caipira e 12,4 na Thap-Maeo, ao passo que o número de frutos no cacho foi de 97 na Pacovan-Ken, 169 na Caipira e 206 na Thap-Maeo (Tabela 4). Estes valores são compatíveis com os dados encontrados por Oliveira et al. (2008). A massa de frutos e a massa dos cachos não apresentaram diferenças significativas entre as variedades. Como observado por Silva et al. (2003), o número de frutos e de pencas por cacho não apresentam uma relação perfeita com a massa do cacho, uma vez que essa depende também do tamanho do fruto. A variedade Thap-Maeo apresentou o maior número de frutos no cacho e o maior número de pencas, a variedade Pacovan-Ken o menor número de frutos no cacho e o menor número de pencas, todavia não ocorreram diferenças significativas na massa dos frutos nem na produtividade entre as três variedades.

Os frutos da variedade Pacovan-Ken são do tipo Prata, mas tendem a ser maiores e mais pesados do que das demais variedades. Este tipo de fruto é mais apreciado pelo consumidor da região Nordeste do Brasil. Para Belalcázar Carvajal (1991), o tamanho e a forma do cacho são fatores condicionados geneticamente, porém o número de pencas e de frutos pode ser influenciado por condições ambientais adversas, que ocorreram na época da diferenciação, como desfolha severa e outros fatores.

As produtividades obtidas neste trabalho foram consideradas elevadas e talvez poderiam ser ainda superiores, considerando as deficiências físico-químicas do solo, constatadas na área da experimentação. Segundo Silva \& Borges (2008), a bananeira é uma planta muito exigente em nutrientes, principalmente em potássio e nitrogênio; e, nas condições do presente trabalho, o solo apresentou teores baixos de potássio e de matéria orgânica e elevada acidez. A variedade Pacovan-Ken apresentou a produtividade de 26,98 t.ha-1 , a Caipira de 24,78 t.ha- ${ }^{-1}$ e a Thap-Maeo produziu 28,39 t.ha ${ }^{-1}$. Estes valores são muito superiores à media de 14,614 t.ha ${ }^{-1}$ em Minas Gerais (Agrianual, 2007) e à média de 21,263 t.ha-1 da região norte mineira (IBGE, 2008). As três variedades foram consideradas com bom potencial para o produtor, entretanto deve-se ressaltar que ainda há dificuldades comerciais quanto à aceitação dos frutos pelos consumidores. 
BANANA

\begin{tabular}{|c|c|c|c|c|c|c|c|c|c|c|c|c|c|c|c|c|c|c|c|c|c|c|c|c|c|c|c|c|c|c|c|c|c|c|c|c|c|}
\hline \multicolumn{6}{|c|}{$P I$} & \multicolumn{4}{|c|}{$\mathrm{Cl}$} & \multicolumn{5}{|c|}{ TMI } & \multicolumn{4}{|c|}{ P II } & \multicolumn{3}{|c|}{$C \|$} & & \multicolumn{3}{|c|}{ TM II } & \multicolumn{4}{|c|}{ P III } & & \multicolumn{3}{|c|}{$C$ III } & \multicolumn{4}{|c|}{ TM III } \\
\hline & 0 & & 0 & 0 & 0 & 0 & $\circ$ & 0 & 0 & 0 & & 0 & & & 0 & & 0 & 0 & & 0 & & & 0 & $\circ$ & 0 & 0 & 0 & $\%$ & & & $\%$ & & & $\%$ & $\%$ & & \\
\hline 0 & 01 & & 04 & 0 & 。 & 0 & $\circ$ & 。 & 。 & 0 & & 0 & 0 & 0 & 0 & & 0 & 。 & 0 & 0 & 0 & 。 & 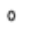 & 。 & 0 & 。 & 0 & 0 & 0 & 0 & 0 & 。 & 0 & 0 & 0 & 。 & 。 \\
\hline 0 & 02 & $\mathrm{~T}$ & 05 & 0 & 0 & $\circ Q$ & Q $\quad 0$ & 。 & 。 & 0 & M & 0 & 0 & 0 & 。 & Q & 0 & 0 & o & Fo & 0 & 0 & 0 & Q。 & 0 & 0 & $\circ F$ & $F \quad 0$ & 0 & 0 & 。 & FC & 0 & 0 & 0 & Mo & $\circ$ \\
\hline 0 & 03 & & 06 & 0 & 0 & 0 & 0 & 0 & 0 & 0 & & 0 & 0 & 0 & 0 & & 0 & 0 & 0 & 。 & 0 & 0 & 0 & 。 & 0 & 0 & 0 & 0 & 0 & 。 & 0 & & 0 & 。 & 0 & ${ }^{\circ}$ & 0 \\
\hline 0 & 0 & & 0 & 0 & 0 & 0 & 0 & 0 & 0 & 0 & & o & 0 & 0 & 0 & & 0 & 0 & 0 & 0 & 0 & 0 & 0 & ० & 0 & 0 & 0 & 0 & 0 & 0 & 0 & & 0 & 0 & 0 & 0 & 0 \\
\hline 0 & 0 & & 0 & 0 & 0 & 0 & o & 0 & 0 & 0 & & 0 & 0 & 0 & 0 & & 0 & 0 & 0 & 0 & 0 & 0 & 0 & 8 & 0 & 0 & 0 & 0 & 0 & 0 & 0 & & 00 & 0 & 0 & 。 & 0 \\
\hline 0 & 0 & $\mathbf{F}$ & 。 & 0 & 0 & $0 \mathrm{M}$ & 40 & 。 & 。 & $\circ$ & FC & 。 & 。 & 。 & 0 & $\mathbf{T}$ & 0 & 。 & 。 & M。 & 0 & 。 & 0 & $F 。$ & 。 & 。 & $\circ \mathrm{T}$ & $\begin{array}{ll}\Gamma & 0\end{array}$ & 。 & 。 & 。 & M & 00 & 。 & 。 & Q。 & 。 \\
\hline 0 & 0 & & 0 & 0 & 0 & 0 & 0 & 0 & 0 & 0 & & 0 & 0 & 0 & 0 & & 0 & 0 & 0 & 0 & 0 & 0 & 0 & $\circ$ & 0 & 0 & 0 & 0 & 0 & 0 & 0 & & 0 & 0 & 0 & $\circ$ & 0 \\
\hline 0 & 0 & & 0 & 0 & 0 & 0 & 0 & 0 & 0 & 0 & & 0 & 0 & 0 & 0 & & 0 & 0 & 0 & 0 & 0 & 0 & 0 & $\circ$ & 0 & 0 & 0 & 0 & 0 & 0 & 0 & & 0 & 0 & 0 & 0 & 0 \\
\hline 0 & 0 & & 0 & 0 & 0 & 0 & $\circ$ & 0 & 0 & 0 & & 0 & 0 & 0 & 0 & & 0 & 0 & 0 & 0 & 0 & 0 & 0 & $\circ$ & 0 & 0 & 0 & 0 & 0 & 0 & 0 & & 0 & 0 & 0 & o & 0 \\
\hline 0 & 0 & Q & 0 & 0 & 0 & $0 \quad F$ & $F \quad 0$ & 0 & 0 & 0 & $\mathbf{T}$ & 0 & 0 & 0 & 01 & FC & 0 & 0 & 0 & $\mathbf{T} 0$ & 0 & 0 & 0 & FC。 & 0 & 0 & $\circ Q$ & $2 \quad 0$ & 0 & 0 & 0 & $\mathbf{F}$ & $0 \quad 0$ & 0 & 0 & FC 0 & 0 \\
\hline 。 & 0 & & 0 & 0 & 0 & 0 & 。 & 0 & 0 & 0 & & 0 & 0 & 0 & 0 & & 0 & 。 & 0 & 0 & 0 & 0 & 0 & $\circ$ & 0 & 0 & 0 & 0 & 0 & 0 & 。 & & 00 & 0 & 0 & o & $\circ$ \\
\hline 0 & 0 & & 0 & 0 & 0 & 0 & 。 & 0 & 0 & 0 & & 0 & 0 & 0 & 0 & & 0 & 0 & 0 & 0 & 0 & 0 & 。 & 。 & 0 & 0 & 0 & 0 & 0 & 0 & 0 & & $0 \quad 0$ & 0 & 0 & o & 。 \\
\hline 0 & 0 & & 0 & 0 & 0 & 0 & o & 0 & 0 & 0 & & 0 & 0 & 0 & 0 & & 0 & 0 & 0 & 0 & 0 & 0 & 0 & 。 & 0 & 0 & 0 & 0 & 0 & 0 & 0 & & 00 & 0 & 0 & 0 & 0 \\
\hline 0 & 0 & $\mathbf{M}$ & & 0 & 0 & $\circ \mathrm{FC}$ & $\begin{array}{ll}C & 0\end{array}$ & 0 & 0 & 0 & Q & 0 & 0 & 0 & 0 & M & 0 & 0 & 0 & Q O & 0 & 0 & 0 & $T \circ$ & 0 & 0 & $0 \mathrm{M}$ & $\begin{array}{lll}1 & 0\end{array}$ & 0 & 0 & 0 & T & 00 & 0 & 0 & $F \quad 0$ & 。 \\
\hline 0 & 0 & & 0 & 0 & 0 & 0 & 0 & 0 & 0 & 0 & & 0 & 0 & 0 & 0 & & 0 & 0 & 0 & 0 & 0 & 0 & 0 & 0 & 0 & 0 & 0 & 0 & 0 & 0 & 0 & 。 & $0 \quad 0$ & 0 & 0 & 0 & 0 \\
\hline 0 & 0 & & 0 & 0 & 0 & 0 & 。 & 0 & 0 & 0 & & 0 & 0 & 0 & 0 & & 0 & 0 & 0 & 0 & 0 & 0 & 0 & ० & 0 & 0 & 0 & 0 & 0 & 0 & 0 & 。 & 00 & 0 & 0 & 0 & 0 \\
\hline 0 & 0 & & 0 & 0 & 0 & 0 & 。 & 0 & 0 & 0 & & 。 & 0 & 0 & 0 & & 0 & 0 & 0 & 0 & 0 & 0 & 0 & 。 & 0 & 0 & 0 & 0 & 0 & 0 & 0 & 。 & 00 & 。 & 0 & 0 & 0 \\
\hline$\circ$ & 0 & FC & & 。 & 0 & $\circ \mathbf{T}$ & $\begin{array}{r}1 \\
\end{array}$ & 。 & 0 & 0 & $\mathbf{F}$ & 0 & 0 & 0 & 0 & $\mathbf{F}$ & 0 & 0 & 。 & FCo & 0 & 0 & 0 & M。 & 0 & 。 & $\circ \mathrm{FC}$ & C O & 0 & 。 & 0 & Q & $0 \quad 0$ & 。 & 0 & $\mathbf{T} \quad 0$ & 。 \\
\hline ० & 。 & & 0 & 0 & 0 & 0 & 。 & 0 & 0 & 0 & & 。 & 0 & 。 & 0 & & 0 & 0 & 。 & 0 & 0 & 。 & 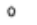 & 。 & 0 & 。 & 0 & 0 & 。 & 。 & 。 & . & 0 & 。 & 0 & 。 & 。 \\
\hline & 0 & & & 0 & 0 & 0 & 0 & 0 & 0 & 0 & & 0 & 0 & 0 & 0 & & 0 & 0 & 0 & 0 & 0 & 0 & 0 & 0 & 0 & 0 & 0 & 0 & 0 & 0 & 0 & & 00 & 0 & 0 & 0 & \\
\hline
\end{tabular}

\begin{tabular}{|c|c|c|c|c|}
\hline Legenda: & $\begin{array}{l}\text { P - Pacovan-Ken } \\
\text { C - Caipira } \\
\text { TM - Thap_Maeo }\end{array}$ & I, II e III - Blocos & $\begin{array}{l}\text { F - Feijão } \\
\text { Q - Quiabo } \\
\text { M - Melancia }\end{array}$ & $\begin{array}{l}\text { FC - Feijão-Caupi } \\
\text { T - Testemunha }\end{array}$ \\
\hline
\end{tabular}

FIGURA 1- Distribuição das parcelas na área experimental, com três variedades de bananeiras, quatro culturas intercalares e a testemunha, em Janaúba-MG, 2006.

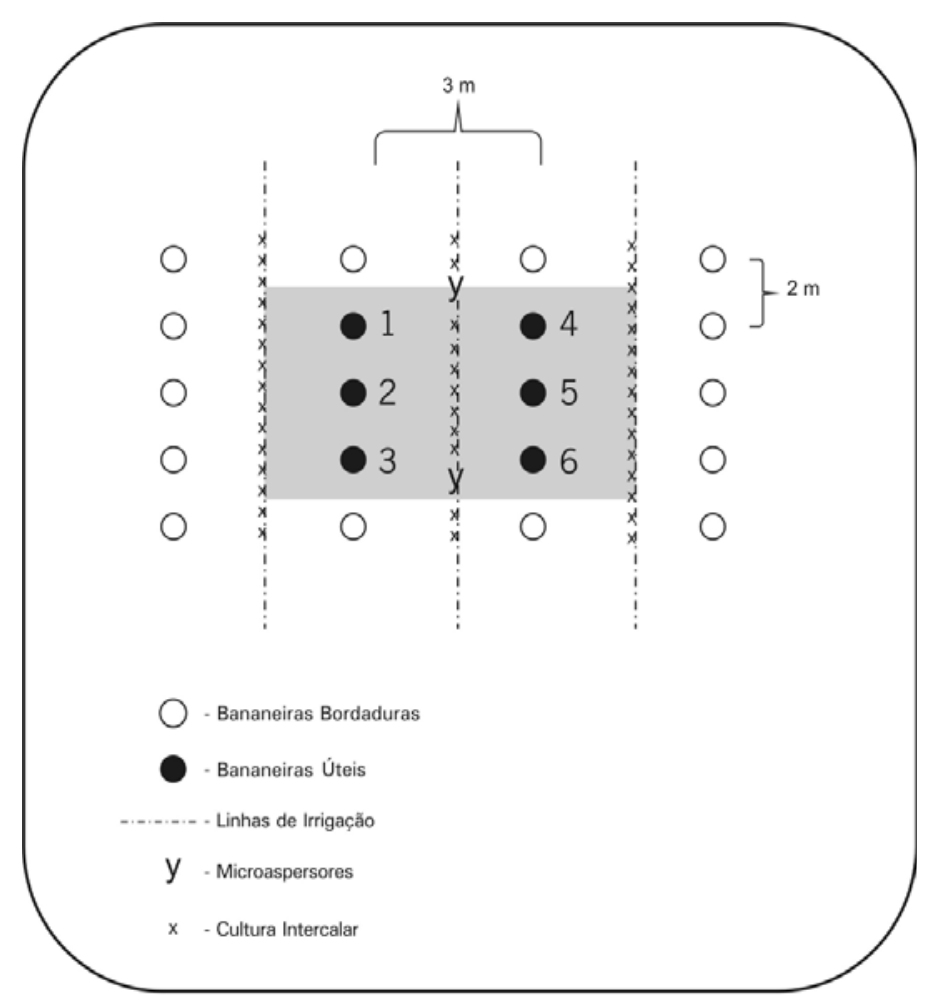

FIGURA 2 - Esquema da parcela experimental, em Janaúba-MG, 2006. 
TABELA 1- Valores médios da altura das plantas (ALT), perímetro do pseudocaule ao nível do solo (PPNS), perímetro do pseudocaule a $30 \mathrm{~cm}$ do solo (PP30), número de folhas vivas no florescimento (NFF) e na colheita (NFC), de bananeiras Pacovan-Ken, Caipira e Thap-Maeo, submetidas a diferentes sistemas de consorciação, em Janaúba-MG, 2007.

\begin{tabular}{lccccc}
\hline Variedades & $\begin{array}{c}\text { ALT } \\
(\mathrm{m})\end{array}$ & $\begin{array}{c}\text { PPNS } \\
(\mathrm{m})\end{array}$ & $\begin{array}{c}\text { PP30 } \\
(\mathrm{m})\end{array}$ & NFF & NFC \\
\hline Pacovan-Ken & $3,51 \mathrm{a}$ & $0,84 \mathrm{a}$ & $0,73 \mathrm{a}$ & $15,5 \mathrm{a}$ & $9,2 \mathrm{a}$ \\
Caipira & $2,67 \mathrm{c}$ & $0,72 \mathrm{c}$ & $0,64 \mathrm{c}$ & $13,1 \mathrm{~b}$ & $9,2 \mathrm{a}$ \\
Thap-Maeo & $3,15 \mathrm{~b}$ & $0,79 \mathrm{~b}$ & $0,70 \mathrm{~b}$ & $14,7 \mathrm{a}$ & $9,9 \mathrm{a}$ \\
\hline CV (\%) & 6,81 & 4,36 & 4,48 & 5,47 & 7,59 \\
\hline
\end{tabular}

Médias seguidas pela mesma letra nas colunas não diferem entre si, a 5 \% de probabilidade, pelo teste de Tukey.

TABELA 2 - Valores médios do número de dias do plantio ao florescimento (NDPF), do número de dias do florescimento à colheita (NDFC) e do número de dias do plantio à colheita (NDPC), de bananeiras Pacovan-Ken, Caipira e Thap-Maeo, submetidas a diferentes sistemas de consorciação, em Janaúba-MG, 2007.

\begin{tabular}{lccc}
\hline Tratamentos & NDPF & NDFC & NDPC \\
\hline Culturas Intercalares & $275 \mathrm{~b}$ & $120 \mathrm{a}$ & $395 \mathrm{ab}$ \\
Testemunha & $282 \mathrm{ab}$ & $116 \mathrm{a}$ & $393 \mathrm{~b}$ \\
Quijão-Pérola & $284 \mathrm{ab}$ & $116 \mathrm{a}$ & $397 \mathrm{ab}$ \\
Melancia-Crimson & $273 \mathrm{~b}$ & $121 \mathrm{a}$ & $392 \mathrm{~b}$ \\
Sweet & $295 \mathrm{a}$ & $117 \mathrm{a}$ & $410 \mathrm{a}$ \\
Feijão-Caupi & 4,67 & 7,74 & 3,02 \\
\hline CV (\%)
\end{tabular}

Médias seguidas pela mesma letra nas colunas não diferem entre si, a 5\% de probabilidade, pelo teste de Tukey.

TABELA 3 - Valores médios do número de dias do plantio ao floresc. (NDPF) do número de dias do florescimento à colheita (NDFC) e do número de dias do plantio à colheita (NDPC), das bananeiras Pacovan-Ken, Caipira e Thap-Maeo, submetidas a diferentes sistemas de consorciação, em Janaúba-MG, 2007.

\begin{tabular}{lccc}
\hline Variedades & NDPF & NDFC & NDPC \\
\hline Pacovan-Ken & $269 \mathrm{c}$ & $129 \mathrm{a}$ & $394 \mathrm{ab}$ \\
Caipira & $293 \mathrm{a}$ & $116 \mathrm{ab}$ & $408 \mathrm{a}$ \\
Thap-Maeo & $283 \mathrm{~b}$ & $109 \mathrm{~b}$ & $390 \mathrm{~b}$
\end{tabular}

Médias seguidas pela mesma letra nas colunas não diferem entre si, a 5\% de probabilidade, pelo teste de Tukey.

TABELA 4 - Valores médios da massa do engaço (PE), da circunferência do engaço (CE), número de pencas dos cachos (NP), número de frutos dos cachos (NFR), massa dos frutos dos cachos (MF), massa dos cachos (MC) e produtividade (PROD), das variedades Pacovan-Ken, Caipira e Thap-Maeo, submetidas a diferentes sistemas de consorciação, em Janaúba-MG, 2007.

\begin{tabular}{lccccccc}
\hline Variedades & $\begin{array}{c}\text { PE } \\
(\mathrm{kg})\end{array}$ & $\begin{array}{c}\mathrm{CE} \\
(\mathrm{cm})\end{array}$ & NP & NFR & $\begin{array}{c}\text { MF } \\
(\mathrm{kg})\end{array}$ & $\begin{array}{c}\text { MC } \\
(\mathrm{kg})\end{array}$ & PROD (t.ha-1 $)$ \\
\hline Pacovan-Ken & $2,600 \mathrm{a}$ & $21,66 \mathrm{a}$ & $7,1 \mathrm{a}$ & $97 \mathrm{c}$ & $16,196 \mathrm{a}$ & $18,808 \mathrm{a}$ & $26,98 \mathrm{a}$ \\
Caipira & $2,390 \mathrm{ab}$ & $20,58 \mathrm{~b}$ & $8,7 \mathrm{~b}$ & $169 \mathrm{~b}$ & $14,877 \mathrm{a}$ & $17,285 \mathrm{a}$ & $24,78 \mathrm{a}$ \\
Thap-Maeo & $2,211 \mathrm{~b}$ & $19,51 \mathrm{c}$ & $12,4 \mathrm{c}$ & $206 \mathrm{a}$ & $17,043 \mathrm{a}$ & $19,268 \mathrm{a}$ & $28,39 \mathrm{a}$ \\
\hline CV (\%) & 12,78 & 5,13 & 5,17 & 9,24 & 11,90 & 11,48 & 11,90 \\
\hline
\end{tabular}

Médias seguidas pela mesma letra nas colunas não diferem entre si, a 5\% de probabilidade, pelo teste de Tukey. 


\section{CONCLUSÕES}

1-Entre as três variedades avaliadas, a Pacovan-Ken apresentou maior porte e a Caipira o menor, independentemente da cultura intercalar.

2-A variedade Caipira apresentou o maior ciclo de produção.

3-O consórcio não afetou as características vegetativas e reprodutivas das variedades PacovanKen, Caipira e Thap-Maeo, com exceção do uso do feijão-caupi, o qual promoveu atraso no ciclo de produção das três variedades de bananeiras.

\section{REFERÊNCIAS}

AGRIANUAL 2007: anuário da agricultura brasileira. São Paulo: FNP Consultoria e Comércio, 2006. p.194-204.

ALVES, E.J. (Org.). A Cultura da banana: aspectos técnicos, socioeconômicos e agroindustriais. 2.ed. Cruz das Almas: EMBRAPA-CNPMF, 1999. 585p.

ANTUNES, F.Z. Caracterização climática. Informe Agropecuário, Belo Horizonte, v.17, n.181, p.1519. 1994.

BELALCÁZAR CARVAJAL, S.L. El cultivo del plátano em el trópico. Cali: Colômbia. Impressora Feriva, 1991. 376p.

CARVALHO, J.E.B.. SOUZA, L.S.; CALDAS, R.C.; ANTAS, P.E.U.T.; ARAÚJO, A.M.A.; LOPES, L.C.; SANTOS, R.C.; LOPES, N.C.M.; SOUZA, A.L.V. Leguminosa no controle de plantas daninhas para aumentar a produtividade de laranja-Pera. Revista Brasileira de Fruticultura, Jaboticabal, v.24, n.1, p.82-85, 2002b.

CASASSANTA, N. M. A bananicultura no norte de Minas e seus efeitos na economia regional. In: SIMPÓSIO NORTE MINEIRO SOBRE A CULTURA DA BANANA, 1., 2001, Nova Porteirinha. Anais... Montes Claros: Ed. Unimontes, 2001. p. 180-187.

CORDEIRO, Z. J. M.; DIAS, M. S. C. BORGES, A. L; XAVIER, A. A.; SILVA, J. T.A. da; OLIVEIRA, S. L. de; FANCELLI, M.; RITZINGER, C. H. S. P.; PEREIRA, M.E.C.; LIMA, M. B.; RODRIGUES, M. G. V.; COSTA, E. L. Controle da sigatoka-amarela na PI da banana (PIB) no norte de Minas Gerais. In: SEMINÁRIO BRASILEIRO DE PRODUÇÃO INTEGRADA DE FRUTAS, 8., 2006, Vitória. Anais... Vitória: INCAPER, 2006. p.179-180.
CORDEIRO, Z.J.M. Banana: produção, aspectos técnicos. Brasília: Embrapa Comunicação Para Transferência De Tecnologia, 2000. cap.1, p.9-11. (Frutas do Brasil, 1).

DONATO, S.L.R.; SILVA, S.O.; LUCCA FILHO, A.L.; LIMA, M.B.; DOMINGUES, H.; ALVES, J.S. Comportamento de variedades e híbridos de bananeira (Musa spp.), em dois ciclos de produção no sudoeste da Bahia. Revista Brasileira de Fruticultura, Jaboticabal, v.28, n.1, p.139-144, 2006.

FAO - Food and Agriculture Organization the Units Nations. Cultivos bananos. Cantidat de producción. Rome. In: FAOSTAT. FAO statistical data bases: Cantidad de producción. 2007.. Disponível em: $<$ http://faostat.fao.org >. Acesso em: 10 set. 2008.

GONÇALVES, V.D.; NIETSCHE, S.; PEREIRA, M.C.T.; SILVA, S.O.; SANTOS, M.; OLIVEIRA, J.R.; FRANCO, L.R.L.; RUGGIERO, C. Avaliação das cultivares de bananeira Prata-Anã, Thap-Maeo e Caipira em diferentes sistemas de plantio no norte de Minas Gerais. Revista Brasileira de Fruticultura, Jaboticabal, v. 30, p. 371-376, 2008.

IBGE - Instituto Brasileiro de Geografia e Estatística. Levantamento sistemático da produção agrícola - LSPA. 2008. Disponível em: <http://www.sidra. ibge.gov.br>. Acesso em: 08 set. 2008.

MOREIRA, R.S. Tratos culturais. In: MOREIRA, R S. Banana: teoria e prática de cultivo. 2. ed. São Paulo: Fundação Cargill, 1999. cap. 6. CD-ROM.

OLIVEIRA, S. de O.; PEREIRA, L. V.; RODRIGUES, M.G.V. Variedades. Informe Agropecuário, Belo Horizonte, v.29, n.245, p. 78-83, 1997.

PEREIRA, M.C.T. Crescimento e produção de primeiro ciclo da bananeira (Musa spp.) PrataAnã (AAB) em sete espaçamentos, em Jaíba e Visconde do Rio Branco-MG. 1997. 56 f. Dissertação (Mestrado em Fitotecnia) - Universidade Federal de Viçosa, Viçosa, 1997.

RODRIGUES, M.G.V.; SOUTO, R. R.; SILVA, S. de O. Avaliação de genótipos de bananeira sob irrigação. Revista Brasileira de Fruticultura, Jaboticabal, v. 28. n.3. 2007. 
SANTOS, S. C.; CARNEIRO, L.C.; SILVEIRA NETO, A.N.; PANIAGO JÚNIOR, E.; FREITAS, H.G.; PEIXOTO, C.N. Caracterização morfológica e avaliação de cultivares de bananeira resistentes à sigatoka-negra (Mycosphaerella fijiensis Morelet) no Sudoeste Goiano. Revista Brasileira de Fruticultura, Jaboticabal, v. 28, n.3. 2007.

SILVA, J.T.A.; BORGES, A.L. Solo, nutrição mineral e adubação da bananeira. Informe Agropecuário, Belo Horizonte, v.29. n. 245, p.25-37, 2008.

SILVA, S.O.; ALVES, E. J.; LIMA, M. B.; SILVEIRA J. R.S. Bananeira. In: BRUCKNER C.H. (Ed.). Melhoramento de fruteiras tropicais. Viçosa: UFV, 2002a. p. 101-157.
SILVA, S. O.; PASSOS, A.R.; DONATO, S.L.R.; SALOMÃO, L.C.C.; PEREIRA, L.V.; RODRIGUES, M.G.V.; LIMA NETO, F. P.; LIMA. M.B. Avaliação de genótipos de bananeira em diferentes ambientes. Ciência e Agrotecnologia, Lavras, v.27, n.4, p. 737-748, 2003.

SILVA, S. O.; ROCHA, S.A.; ALVES, J.A. Caracterização morfológica e avaliação de cultivares e híbridos de bananeira. Revista Brasileira de Fruticultura, Jaboticabal, v.22, n.2, p.161-169. 2000.

TEIXEIRA, L. A. J. Cultivares de Bananeiras. In: RUGGIERO, C. (Coord.). Bananicultura. Jaboticabal: FUNEP, 2001. p. 150-170. 